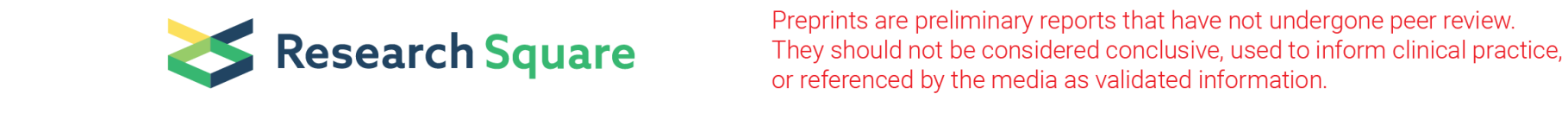

\title{
Challenges in treating cancer in post-conflict Kosovo, a systematic review
}

\author{
Shqipe Hyseni Buleshkaj ( $\square$ shqipe.buleshkaj@rezonanca-rks.com ) \\ ALMA MATER EUROPAEA, Campus Rezonanca, Prishtina, Kosovo. \\ Naser Rugova \\ UBT Higher Education Institution, Prishtina, Kosovo
}

\section{Case Report}

Keywords: Cancer, conflict, statistics, palliative care, reform, Kosovo

Posted Date: January 27th, 2022

DOI: https://doi.org/10.21203/rs.3.rs-1233024/v1

License: (c) (i) This work is licensed under a Creative Commons Attribution 4.0 International License. Read Full License 


\section{Abstract}

Background: The direct and side effects of the impact of the conflict on the general health condition of the population and the health infrastructure are evidenced, measurable as well as fact-based as is the case of Kosovo. These findings are also confirmed by interviews with interviewed health professionals who address this issue. In these 22 years after the conflict and 13 years following the independence, the consequences of the conflict in the health system of Kosovo are obvious in all three levels of its organization. Cancer treatment and palliative care continue to be among the weakest links in Kosovo's health system.

Case presentation: Since the end of the conflict there is a significant increase of cancer cases in Kosovo. This has proven to be a difficult extra burden for an already shattered health system. The main purpose of this study is to explore and analyze the available data on cancer treatment during this post-conflict period in Kosovo, including the causes, age and gender of those endangered by cancer, and measures taken by the Kosovo authorities to treat and contain these cases.

Conclusions: The consequences of the conflict significantly complicate the enhancement and reforms in the health system of a country, especially in the areas of tertiary health care that require political will, sustainable and continuous funding, continuous education of health personnel, therapy based on modern protocols and advanced equipment, which the Kosovo health system and palliative care currently lack.

\section{Background}

Armed conflict is unfortunately a common occurrence throughout history, the recent one as well. In the past twenty-five years, more than fifty countries have experienced conflict. Excess mortality and morbidity, displaced populations, and vulnerability to communicable diseases during and following conflict all call for immediate relief and restoration of basic services. As much as possible, short-term relief and assistance programmes should be implemented in a manner compatible with longer term health system rehabilitation. (Waters et al. 2007). The consequences of the conflict on the health of the population are significant. In addition to the direct effects of the war, there are a number of adverse outcomes through intermediate effects - including the destruction of infrastructure, equipment and supplies, and discontinuation of essential services as in the case of Kosovo. The consequences of the conflict continue to have side effects even two decades after its end. By the year 2020, mortality and morbidity from war are expected to represent the eighth largest category of disease burden worldwide (Krug et al. 2000). Although Kosovo is taken as an example of the relatively rapid rehabilitation of the post-conflict health system by adopting an interim health policy strategy developed by the WHO in consultation with the Kosovar medical community in just three months (LSHTM 2001), the consequences of the devastating conflict are easily noticed even today. Moreover, the post-conflict environment is characterized by highly divisive policies, a weak economy and low government capacity, all of which affect the implementation of efforts to successfully implement health sector reform in post-conflict countries. This context creates a difficult implementation environment (Valerie Percival \& Egbert Sondorp, 2010).

Kosovo is bordered by Macedonia to the East and Southeast, Albania to the Southwest, Montenegro to the West, and Serbia to the North. With a territory of approximately 10,900 square kilometres, Kosovo has predominantly continental climate.

The population of 1.794 million people (Eurostat, 2012) is predominantly rural (about $62 \%$ of the entire population), (Kosovo Agency of Statistics, 2013). Currently, Kosovo is organized into 7 districts, and further divided into 38 municipalities. There are cities, of which 15 have populations larger than 50,000 (Kosovo Agency of Statistics, 2013). Prishtina is the capital and the largest city (with about 201 thousand inhabitants).

During the 1990's Kosovo's socio-economic and political situation was defined by the wars that the Federal Republic of Yugoslavia was involved in, its exclusionary policies towards Kosovo, the related UN imposed economic sanctions, and finally NATO's military intervention. Socioeconomic and political transformations which followed were closely related to the state of welfare emergency that characterized Kosovo in the beginning of the 2000s. International donors' aid provided emergency humanitarian relief and assisted the process of reconstruction. However, after a decade, Kosovo's state of welfare is still characterized by vulnerable labor market, weak old-age protection, and healthcare of poor quality in an underdeveloped system (Marija Stambolieva, 2012).

Kosovo not only endured a devastating war in 1998 and 1999, but for a decade prior to that, medical structures, including the medical education system functioned in a parallel existence to the social insurance system that had existed in Yugoslavia, thus 
leaving health personnel completely isolated. Government health spending is about $3 \%$ of the GDP and $8 \%$ of general government expenditure (Friedrich-Ebert-Stiftung, 2014). Only $60 \%$ of overall health spending is covered by the government budget. The other $40 \%$ is private spending, resulting in significant inequalities in access, and out-of-pocket payments which themselves contribute to increased poverty (Stubbs and Haxhikadrija, 2008). Aside from the passage of the Health Law by the parliament and the government, and the approval of the draft law on health insurance - all of which set the stage for further developing a health insurance plan - no other concrete policy results have materialized until now. Kosovo's health system continues to face significant problems even now 13 years after the declaration of independence in specific areas such as palliative care.

Palliative care is currently delivered in limited forms at all levels of the health care system in Kosovo. At the primary care level, home care teams specializing in chronic care deliver palliative care to home-bound patients. In regional hospitals, patients can seek out "supportive care" treatments between rounds of therapy at University Clinical Center Kosovo (UCCK) or when they no longer have curative options. In clinics at UCCK, doctors provide palliative care treatments to patients in need, but must do so as a secondary focus. In some areas of Kosovo, NGOs have started providing palliative care and home care to patients in need to close some of the gaps in palliative care provision. However, not all gaps in palliative care can be filled by NGOs, leaving many Kosovars without the appropriate palliative care options (Jones et al. 2018).

Though the provision of palliative care is limited, positive aspects of the current system include home care teams at the primary level, supportive care at the secondary level, and the inpatient palliative care unit at the tertiary level at UCCK. These components represent areas of care that can be strengthened and expanded as a foundation for a national palliative care program.

In Kosovo, most diagnostic services are available in private practices. In the public healthcare system, services are free of charge, but the capacity is very limited. Because many people do not have money to pay for the services, delays in visiting the doctor are widespread.

In some cases, patients need to travel abroad to diagnose the disease. Besides the cost of health services, transport related costs increase further the burden on patients, particularly on the poor and on those who live in remote areas and cannot travel during the winter. The treatment of cancer is highly expensive as most services are provided in private sector or must be purchased with out ofpocket payments. Usually, patients have to bring medication and supplies that are needed for treatment. In many cases they have to buy/ bring everything, even clean sheets, in the case of hospitalization. Medication is not only expensive but also unavailable, so people have to obtain it from abroad (through relatives, friends or other connections). Also, there is some indication that people do pay medical staff 'under the counter', which is made easier by the lack of a control mechanism. Thus, the overall costs reported in cancer treatment reach about $€ 10,000$, including travel and accommodation (as against an average national wage of $€ 300$ per month). The situation is even worse in those types of cancer in which treatment is not available within the country (Friedrich-EbertStiftung, 2014).

So, many patients cannot afford the treatment. Health monitoring services are available in the public sector, but only in the country capital in the Institute of Oncology. Accordingly patients who do not live in Prishtina have to travel in order to receive the appropriate services (between 40 and $85 \mathrm{~km}$ one way), hence travel costs represent again an access barrier for many people. If a patient does not have money, s/he may apply to the fund available for treatment abroad (which is very limited, about $€ 3$ million), or may take a loan (from relatives and friends) credit in a bank. Only few people are insured with private health insurance, which usually covers about $80 \%$ of the costs for diagnosis and treatment (Friedrich-Ebert-Stiftung, 2014).

\section{Literature Review}

Conflict is a dispute or incompatibility caused by the actual or perceived opposition of needs, values, and interests. In political terms, conflict refers to wars or other struggles that involve the use of force. The term "conflict" is understood to mean violent conflict. (UNEP, 2009).

Armed conflict is a global health issue. Long-lasting and protracted conflicts in particular have consequences not only for the warwounded but also for the health of entire communities. Over the years, global health actors and humanitarian health actors have developed health policies, guidelines, frameworks, and structures to improve delivery of health services in emergencies or humanitarian crises. Despite these advancements, however, the international health response in conflict-affected settings still faces

Page $3 / 20$ 
gaps and challenges. Some policies and frameworks need to be rethought or redesigned, while others need to be better implemented. (Alice Debarre, 2018).

Post-conflict reconstruction is broadly understood as a complex, holistic and multidimensional process encompassing effort to simultaneously improve military (restoration of law and order), political (governance), economic (rehabilitation and development) and social conditions (justice and reconciliation). (Tzifakis, 2021).

Health is a domain of public services affected by all of the above-mentioned aspects of post-conflict reconstruction. Post-conflict health reform remains an under-researched area, and as such, there are no pre-existing frameworks that analyze how health interventions interact with the post-conflict social, political, and economic environment.

In order to implement the Post Conflict Theory and the Health Promotion model in the case of Kosovo after 1999, the international community took action, investing millions of dollars and much human effort in rebuilding Kosovo and its health sector as quickly as possible. Security community actors such as the UN's Interim Administration Mission in Kosovo (UNMIK), the EU's Rule of Law Mission in Kosovo (EULEX), and NATO's Kosovo Force (KFOR) were involved in the effort throughout, in a variety of different ways and scopes. Health system strengthening is a mix of complex activities, all of which are interconnected and interdependent. This complexity is amplified in the case of a crisis-affected fragile state, as each scenario involves unique factors that require a tailored approach (Harvard Medical School Department of Global Health and Social Medicine, 2013).

The impact of governance, health policies and decision-making in this sector, despite the commitment of the international community and numerous donors, from 1999 to 2008 is characterized by numerous shortcomings in terms of legislation, organization, budget, and adequate planning. This period called as the "emergency phase" until 2004 and then as the "reconstruction phase" until 2008 are generally characterized by insufficiency to meet the health needs of the population, especially in the prevention, treatment, and fight against cancer.

Following the declaration of independence in 2008, despite the drafting of many laws and sublegal acts, sectoral strategies, budget increase in each budget year, the non-priority of the health sector in the adoption of the necessary legal framework, additional financial support for the implementation of legislation these facts that jeopardize the process of reforms in the health sector. The resources available for public health services are the lowest in Europe and the challenge remains to secure financial resources and use them effectively. Productivity is low, efficiency needs to be improved, especially in terms of introducing modern treatment methods such as day care. Capacity utilization is low, and the quality of health services needs to be improved, especially in terms of hospital infections, the use of clinical guidelines and protocols, and patient-centered treatment (Health Sector Strategy, 2017 - 2020). All this data speaks of an inefficient health system, which does not meet the needs of the population, which continues to be in the "phase of re-consolidation" as a result of the conflict, deep political and socio-economic transition that Kosovo as the newest state in Europe is going through.

As there was no orientation framework to analyze the effect of conflict in the field of palliative care and cancer treatment in Kosovo in the post-conflict period to date, we have compiled a literature review to create the perspective of researchers in this field with a special focus on Kosovo. We have focused on reviewing the literature with a particular focus on: the impact of conflict on health, health reform in Southeast Europe and post-conflict peace-building and reconstruction efforts, post-conflict health system rehabilitation, and publications on palliative care and cancer disease management in the health system in Kosovo. During the literature review we were able to identify problems and political, socio-economic, financial barriers, lack of necessary expertise despite an international commitment, numerous donors in the health sector with the social and political context after the conflict in Kosovo. The literature review also established the following hypotheses on the factors that contributed to the unfavorable outcomes and insufficient achievements of palliative care in Kosovo in the post-transition period of armed conflict:

H1. The effects of the destruction of the health system infrastructure during the conflict in Kosovo, the isolation and lack of building the necessary capacity of health personnel, the lack of sustainable funding and the lack of political will of decision makers continue to be serious challenges to the Kosovo health system in general and palliative care in particular.

$\mathrm{H} 2$ : State capacity in the post-conflict period is low and external actors do not recognize the importance of state capacity in health reform, especially in areas of sub-specialist profiles such as oncology and palliative care. 
H3. The consequences of the conflict significantly complicate the enhancement and reforms in the health system of a country, especially in the areas of tertiary health care that require political will, sustainable and continuous funding, continuous education of

health personnel, therapy based on modern protocols and advanced equipment, which the Kosovo health system and palliative care currently lack.

\section{Methodology}

The main purpose of this study is to provide reliable data and analyze this data on cancer during this post-conflict period in Kosovo, including the causes, ages and genders attacked, measures taken by the Kosovo authorities to combat cancer disease.

Through the qualitative method, using open interviews as an instrument and questionnaires in the electronic form for our research, we interviewed health professionals of the Oncology Clinic of the University Clinical Hospital Service of Kosovo in tertiary health care as the only specialized institution that treats cancer in Kosovo. We also interviewed members of the National Cancer Control Board and other health professionals such as oncologists, radio-oncologists, radiologists, pathologists, surgeons and public health specialists who are part of the combat against cancer.

The questionnaire, including the demographic part, consists of 14 questions: five with multiple choice (according to Likert Scale) with a single selection, two with three options (Three-Point Scales - Likert Scale) one with dichotomous choice with a single selection as well as the opportunity for additional comments.

For data analysis we used the statistical and comparative method, we have analyzed the incidence and prevalence of cancer in Kosovo for the period 2015 - 2019, using official statistics and we have also analyzed the budget, GDP for health and budget allocations for cytostatics for this time period.

\section{Palliative Care In Kosovo}

\section{Palliative care in primary health care}

Legally, palliative care is under the jurisdiction of primary care which is administered on the municipal level. Because of this structure, the provision of palliative care varies by municipality and is dependent on the priorities of the current municipal government. Each municipality has a central family medicine center (FMC) with other clinics throughout the rest of the municipality. The FMCs are funded through the Ministry of Finance, based on the municipality's population size. The central clinic may have specialists such as gynecologists and pediatricians, while the other clinics usually only staff general practitioners and family medicine doctors, though this also varies by municipality. The family medicine staff is based on the population, with one doctor and two nurses allocated per 1,000 residents (Jones et al. 2018). The provision of palliative care services at the level of primary health care has no specific and professional organization. In some municipalities of Kosovo, patients with chronic diseases are provided with health services by the teams of Caritas Kosova (Kosovo - Caritas, 2018), an NGO dedicated to improving the quality of life in Kosovo, protecting human rights, and building peace in Kosovo. These teams, as part of caring for the chronically immobile patients with problems of this nature, also offer medical assistance related to palliative care.

\section{Palliative care in secondary health care}

Depending on the type of cancer, the form and method of treatment, then the geographical distance to health institutions, some patients receive palliative care, supportive care, and other non-curative care at the secondary level of the health care system in the regional hospitals of Kosovo. There are seven regional hospitals in the seven of the largest municipalities in Kosovo besides Pristina. UCCK acts as both a secondary and tertiary hospital, serving the secondary level needs of citizens of Pristina while also serving patients from around the country for more complex health care needs. Most patients who receive palliative services at the secondary level are receiving some form of "supportive care." Supportive care at the regional level refers to treatments to address symptoms of cancer or other terminal diseases. The treatments included in supportive care ranged from blood transfusions, treatment with vitamins and fluids, talking with family members about how to feed and treat the patient at home, and ordering therapies that have been prescribed for the patient at the Institute of Oncology at UCCK (Jones et al. 2018).

Page $5 / 20$ 
In the seven regional hospitals of Kosovo that cover secondary health care, there is a lack of professional capacity related to palliative care, lack of motivation for health staff, high cost of therapy and treatment of cancer patients and other administrative and bureaucratic procedures make these health institutions to recommend cancer patients to go to the Institute of Oncology and UCCK Clinics.

\section{Palliative care in tertiary health care}

The only public tertiary care institution in Kosovo is the University Clinical Center of Kosovo (UCCK) in Prishtina. This hospital is the only public health facility in Kosovo where patients can receive cancer therapy. Oncology as a service started much earlier, but there was no Oncology Clinic or Institute and these services were performed in a scattered manner and without a unique system of services. The staff was extremely insufficient. The Institute of Oncology started working on 28 December 2010. In 2013, the Institute of Oncology changed its statute in the Oncology Clinic, a name that it continues to bear to this day. Radiotherapy is a service that was not provided until 2013. In this year, the first treatment with curative radiotherapy started. Services: The Oncology Clinic provides the services of: Chemotherapy, Radiotherapy, Invasive chemotherapy treatment (intravesical, intrapleural therapy), Laboratory (basic services), Cytostatics preparation, Pharmacy and cytostatics depot. This tertiary level institution as the only one of its kind in Kosovo operates with the following staff structure: Staff: 15 Specialist Doctors, 13 Nurses, 8 Radiotherapy Technicians, 3 Laboratory technicians. With the above staff and services, the oncology clinic provides services for 150 to 300 patients per day (Medical Oncology Clinic, UCHSK, 2021).

The vast majority of patients in the Medical Oncology Clinic receive care in a day clinic, but there are some beds dedicated to inpatient care if a patient cannot travel to and from UCCK. After consultation with an oncologist, patients receive care in large rooms dedicated to different treatments. In the same room that someone may be receiving cancer treatment, palliative treatments may also be provided. Such treatments cover pain and symptom management needs that arise from cancer and are offered based on the current resources available to the Medical Oncology Clinic. The providers of palliative care at the tertiary level are mainly the oncologists at the Medical Oncology Clinic at UCCK. In their training, these physicians have been taught how to manage pain caused by cancer and cancer treatments. However, these oncologists have no specialized training in palliative care. From the data mentioned above, it can be seen that the effects of the conflict and the post-conflict transition period have left obvious consequences on the health system in general and on palliative care in particular. The Institute of Oncology was established 11 years after the end of the war in Kosovo, and the service of Radiotherapy 14 years after the end of the war, it is also worrying that only 39 health professionals have to care for an average of about 200 patients treated per day. The lack of medicines and equipment in public sector clinics often leads to patients paying for their medicines and equipment out-of-pocket from private pharmacies. This failure of public procurement causes increased spending by patients, impacts the quality of care, and forces patients or their families to exit the public system to get necessary supplies (Jones et al. 2018).

In addition to professional medical care, which patients receive from specialists, psychological support has a great significance, unfortunately this care for cancer patients in Kosovo and in general in palliative care is deficient, it is not comprehensive and there is no concrete strategy and action plan from the responsible institutions.

Most patients do not know about palliative care and do not discuss non-curative options with their doctors or families. There is a lack of health education and promotion programs in this area. There have been no studies on the knowledge of palliative care among patients, but studies on knowledge of health care rights reveal gaps in knowledge that affect access to quality care. According to survey responses reported in a 2016 study, most patients lack basic knowledge about their health care rights and particularly the right to pain and symptom management. Approximately 47.1 percent of respondents replied "no" when asked the question, "Have you ever heard of rights of patients in Kosovo?" (Jones et al. 2018). Only 20 percent of respondents said that they believed that they as a patient are entitled to the "right to avoidance [of] suffering and pain." (Jones et al. 2018). In general, rates of responding positively to knowing about different patients' rights are low, with the highest positive response rate around 50 percent. Nonetheless, over 50 percent of respondents said that they do feel they are entitled to the "right of access to health care services." (Jones et al. 2018). As knowledge about patients' right to health care rises, it is crucial to educate the population on their rights to all kinds of care - including palliative care. All this data is a result of doctor-patient communication but also the tradition of communication as a result of inadequate education and health communication in transition countries such as Kosovo. 


\section{Statistics of cancer during the period 2015 - 2019 in Kosovo at all three levels of the health system, statistics of deaths from cancer during this period}

Cancer is the second leading cause of death globally. The number of new cancer patients in the world is in constant growth. According to the WHO, the number of new cases in 2018 was 18.1 million, 9.6 million people died and 43.8 million people are living with cancer (WHO, 2018). It has to be noted that approximately $70 \%$ of cancer deaths come from low- and middle-income countries (LMICs) (WHO, 2021). This data does not include complete and accurate data on cancer statistics in Kosovo, as Kosovo is not yet a member of the UN and as a result is not a member of the WHO, which also has its genesis in unresolved political problems since the end of the war with Serbia. Nevertheless, we will reflect the statistics collected and processed by relevant institutions of Kosovo such as the Kosovo Agency of Statistics for the period of time we are dealing with but also official data from the Ministry of Health of the Republic of Kosovo related to the budget allocated for public health, GDP and the budget spent on cytostatics for the period 20152019.

Mortality from malignant diseases in Kosovo is relatively high, the causes of death from malignant diseases ranked second after diseases of the blood circulatory system.

In 2015, a total of 8989 deaths were reported. Of these, 5169 or $57.5 \%$ male and 3820 or $42.5 \%$ female. As for deaths in Kosovo, according to the classification of disease groups and participation per 100,000 inhabitants, in 2015 we have the following data: From malignant diseases a total of 1079 cases, $14.7 \%$ or 60.9 deaths per 100,000 inhabitants, which is the second highest percentage of causes of death from disease groups after diseases of the circulatory system which have a percentage of $62.7 \%$ or 260 deaths per 100,000 inhabitants (Kosovo Agency of Statistics, 2018).

In 2016, in Kosovo are reported a total of 9245 deaths. Of these, 5300 or $57.3 \%$ male, and $42.7 \%$ or 3945 female. As for deaths in Kosovo, according to the classification of disease groups and participation per 100,000 inhabitants, in 2015 we have the following data: From malignant diseases a total of 1074 cases, $14.5 \%$ or 60.2 deaths per 100,000 inhabitants, which is the second highest percentage of causes of death from disease groups after diseases of the circulatory system which have a percentage of $61.0 \%$ or 253.7 deaths per 100,000 inhabitants (Kosovo Agency of Statistics, 2019).

In 2017 , according to the coding of cause of death, the first place by rank was Diseases of the circulatory system with $48.1 \%$ (participation in the total number of deaths diagnosed), followed by the group of diseases Neoplasms tumors with $11.4 \%$, the third place occupy the group of Diseases of respiratory system by $6.9 \%$, and so on according to the tabular presentation. Of total deaths 9670, of them diagnosed (coded) are 7536 or $77.9 \%$ and undiagnosed (undoced) 2134 or $22.1 \%$ (Kosovo Agency of Statistics, 2019).

In 2018, according to the codification of the cause of death, the first place in the ranking is occupied by Diseases of the circulatory system, with $46.7 \%$ (participation in the total number of deaths with diagnosis), the second place is occupied by the group of Diseases Symptoms, signs and abnormal clinical and laboratory results not classified elsewhere by $28 \%$, Tumors by $11.3 \%$, third place.

In 2019, in Kosovo are reported a total of 10561 deaths, 5838 of them or $55.3 \%$ were males and 4723 or $44.7 \%$ females. according to the codification of the cause of death, the first place according to the ranking is occupied by Diseases of the circulatory system with $51.1 \%$ (participation in the total number of diagnosed deaths), the second place is occupied by the group of Diseases Neoplasms tumors with $19.4 \%$ (Kosovo Agency of Statistics, Metadata, Health Statistics, 2020).

This is the number of deaths from cancer by year: In 2015, 2469 cases were identified, in 2016, a total of 2514 cases, in 2017 a total of 2902 cases in 2018 a total of 2475 cases and in 2019 a total of 2048 cases, since the demographic aspect of the population is a very high number (Kosovo Agency of Statistics, 2020).

Causes of death results are processed analytically and with standards according to the classifications recommended by the World Health Organization (WHO) and Eurostat. From these statistics for the time period we have analyzed, it results that malignant 
diseases or "Tumors" occupy the second place in the ranking of causes of death in Kosovo and this is an additional argument that confirms the hypotheses raised about the consequences of the conflict in the health system of Kosovo even 22 years after its end.

In addition to the statistics of deaths from cancer in Kosovo, we have considered it important to present the budget allocations for the health system for the period 2015-2019, GDP for health and the budget allocated for cytostatics by the Ministry of Health for this period.

\section{Table no. 1}

Public Sector Expenditures on Health, 2015-2019:

\begin{tabular}{llllll} 
Institution & $\mathbf{2 0 1 9}$ & $\mathbf{2 0 1 8}$ & $\mathbf{2 0 1 7}$ & $\mathbf{2 0 1 6}$ & $\mathbf{2 0 1 5}$ \\
\hline Ministry of Health & $27,083,837.63$ & $58,559,449$ & $57,584,100$ & $49,882,445$ & $31,722,673$ \\
\hline UCHSK & $124,661,187.16$ & $84,993,519$ & $70,553,112$ & $69,230,624$ & $86,142,316$ \\
\hline Municipalities (KPSH) & $\mathbf{6 1 , 8 8 2 , 5 2 2 . 9 7}$ & $57,290,744$ & $52,241,181$ & $51,295,600$ & $51,249,067$ \\
\hline FSSH & $9,833,327.39$ & & & & \\
\hline Other ministries & & $1,237,309$ & & & \\
\hline Total & $\mathbf{2 2 3 , 4 6 0 , 8 7 5 . 1 5}$ & $\mathbf{2 0 2 , 0 8 1 , 0 2 1}$ & $\mathbf{1 8 0 , 3 7 8 , 3 9 3}$ & $\mathbf{1 7 0 , 4 0 8 , 6 6 9}$ & $\mathbf{1 6 9 , 1 1 4 , 0 5 6}$
\end{tabular}

Source: Ministry of Health of Republic of Kosovo, 2021.

From Table no. 1. It can be seen that from 2015 - 2019 there has been a trend of increasing health expenditures in the public sector.

Table 2

Percentage of GDP for health 2015 -2019 


\begin{tabular}{|c|c|c|c|c|c|c|}
\hline & 2019 & 2018 & 2017 & 2016 & 2015 & Note \\
\hline Nominal GDP & 7110.5 & $6,726.0$ & $6,413.9$ & $6,070.1$ & $5,807.5$ & $\begin{array}{l}\text { Source: years } \\
\text { 2015-2018: KAS; } \\
\text { year 2019: based } \\
\text { on the } \\
\text { estimation of the } \\
\text { Macroeconomics } \\
\text { Division in MFT }\end{array}$ \\
\hline $\begin{array}{l}\text { Final consumption of } \\
\text { households }\end{array}$ & $6,010.9$ & $5,738.4$ & $5,369.9$ & $5,194.1$ & $4,942.9$ & $\begin{array}{l}\text { Source: years } \\
\text { 2015-2018: KAS; } \\
\text { year 2019: based } \\
\text { on the } \\
\text { estimation of the } \\
\text { Macroeconomics } \\
\text { Division in MFT }\end{array}$ \\
\hline $\begin{array}{l}\text { Private expenditures on } \\
\text { health (\% of final household } \\
\text { consumption) }\end{array}$ & $(3.0 \%)$ & $(3.0 \%)$ & $(3.0 \%)$ & $(3.0 \%)$ & $(3.0 \%)$ & Source: KAS. \\
\hline $\begin{array}{l}\text { Private expenses (million } \\
\text { Euro) }\end{array}$ & $180,326,809$ & $172,152,000$ & $161,097,000$ & $155,823,000$ & $148,287,000$ & $\begin{array}{l}\text { Calculation = } \\
\text { Final } \\
\text { consumption of } \\
\text { households x } \\
\text { Private } \\
\text { expenditures (\% } \\
\text { of final } \\
\text { consumption of } \\
\text { households) }\end{array}$ \\
\hline$\%$ of GDP for public health & $(3.1 \%)$ & $(3.0 \%)$ & $(2.8 \%)$ & $(2.8 \%)$ & $(2.9 \%)$ & $\begin{array}{l}\text { Calculation = } \\
\text { Total Public } \\
\text { Expenditure on } \\
\text { Health / Nominal } \\
\text { GDP }\end{array}$ \\
\hline $\begin{array}{l}\% \text { of GDP for private health } \\
\text { expenditures }\end{array}$ & $(2.5 \%)$ & $(2.6 \%)$ & $(2.5 \%)$ & $(2.6 \%)$ & $(2.6 \%)$ & $\begin{array}{l}\text { Calculation = } \\
\text { Total Private } \\
\text { Expenditure on } \\
\text { Health / Nominal } \\
\text { GDP }\end{array}$ \\
\hline$\%$ of GDP for health & $(5.7 \%)$ & $(5.6 \%)$ & $(5.3 \%)$ & $(5.4 \%)$ & $(5.5 \%)$ & $\begin{array}{l}\text { Calculation = } \\
\text { (Total Public } \\
\text { Expenditure on } \\
\text { Health + Total } \\
\text { Private } \\
\text { Expenditure on } \\
\text { Health) / } \\
\text { Nominal GDP }\end{array}$ \\
\hline
\end{tabular}

Source: Ministry of Health of Republic of Kosovo, 2021.

Table no. 2 reflects the trend of the percentage of GDP during the years 2015 - 2019, where there is a symbolic increase of GDP in the public sector and the same values or even a decrease of the percentage of GDP in the private sector during this period.

Table 3

Budget allocated for cytostatics for UCCK 2016 -2019 


\begin{tabular}{|c|c|c|c|c|}
\hline No. & Financial value of costs for cytostatics & The financial value of planning & Years & Supply percentage \\
\hline 1 & $5,398,167.97$ & $2,816,731.20$ & 2015 & $\begin{array}{l}\text { Data only for the first } 6 \\
\text { months }\end{array}$ \\
\hline 2 & $5,676,346.06$ & $6,371,019.60$ & 2016 & $(89 \%)$ \\
\hline 3 & $6,356,994.41$ & $8,345,333.40$ & 2017 & $(76 \%)$ \\
\hline 4 & $7,134,059.84$ & $8,818,628.64$ & 2018 & $(81 \%)$ \\
\hline 5 & $7,200,321.14$ & $8,313,121.10$ & 2019 & $(87 \%)$ \\
\hline
\end{tabular}

Source: Ministry of Health of Republic of Kosovo, 2021.

Table no. 3. presents the budget allocated for cytostatics for the University Clinical Center of Kosovo (as the only tertiary care institution in Kosovo) during the years 2015 - 2019 reflects an increasing trend for the last three years but the percentage of supply continues not to reach the figure of $90 \%$.

For a more accurate and realistic conclusion of the impact of the conflict on the prevention, treatment and fight against cancer in Kosovo, we have interviewed through open interview and the same content of the interview with officials and professionals in the relevant fields we have developed also through questionnaires in electronic form.

Regarding this issue of the health system of Kosovo, the Director of the Clinic of Medical Oncology at (UCCK), Dr. llir Kurtishi, oncology specialist, estimates that the conflict and especially the period 1990-1999 has greatly damaged the development of oncology in Kosovo. Regarding the trends of advancing oncology after the conflict in Kosovo in the period 1999 - 2019, Dr. Kurtishi estimates that there are great results and advancement in this field of health. Asked whether the health system of Kosovo at all three levels of its organization has the necessary professional profiles and proper infrastructure for the prevention, treatment and fight against cancer, he said that these needs are partially met and there is a need for many more field professionals and other accompanying infrastructure. He considers the coordination of the Ministry of Health, the National Board for Cancer Control and the Oncology Clinic as partially good, with much greater opportunities for coordination, cooperation and increased efficiency in the fight against cancer. As for the approval of the necessary protocols according to modern standards and the application of adequate methods and therapy, he considers that he is relatively satisfied as the director of the Oncology Clinic. To the question whether the health system of Kosovo has palliative care, he has a definite answer: No. Dr. Kurtishi expresses concern about the incidence and prevalence of cancer in Kosovo and blames the Ministry of Health and its policies regarding the current state of prevention, adequate treatment and combating cancer in Kosovo.

Chairwoman of the National Board for Cancer Control, Dr. Dafina Ademi, PhD, Oncology Specialist, for the first two questions has almost the same opinions as the Director of the Oncology Clinic, while in the third question about the necessary profiles and infrastructure she considers it insufficient and separately expresses her concern about lack of continuing professional education for specialists in the fields that deal with this disease and nurses working in this sector. Dr. Ademi also expresses her concern about the small percentage or even lack of screening for some types of cancer as the only method of early cancer diagnosis. In the fourth and fifth question she considers that the coordination between the Ministry of Health, the National Board for Cancer Control and the Oncology Clinic is not good and much more can be done and she also considers that the cancer treatment protocols in the Clinic of Oncology needs to be supplemented and amended because it does not meet contemporary standards of disease treatment. To the question whether there is palliative care in Kosovo, her answer is, no. Regarding the incidence and prevalence of cancer, she expresses concern about the increase in the incidence of this disease in transition countries. Dr. Ademi blames political circumstances and the post-conflict transition and the Ministry of Health for the challenges Kosovo is facing in preventing, adequately treating and combating cancer.

Application of radiotherapy in Kosovo started in 2013. Regarding the issues we are addressing, we interviewed Dr. Emine Devolli Disha, PhD, Oncology and Radiotherapy Specialist. In almost all the questions posed to Dr. Disha - Devolli, she has the same answer as the two interviewees above. She raises the concern about the lack of adequate screening in the early diagnosis of cancer, and 
also her concern is about insufficient technology and equipment that are not of contemporary trends in terms of radiotherapy treatment of cancer. Her concern is also related to the lack of palliative care in Kosovo as an important link after the application of therapy. Regarding the situation in which Kosovo finds itself in terms of early diagnosis, adequate treatment and combating cancer, she considers as a primary effect the socio-economic situation as a direct consequence of the impact of the conflict and inadequate health policies.

Given that in the five years that we have analyzed the incidence of cancer, it turns out that most cases in Kosovo have been identified with breast and respiratory cancer. We have interviewed Dr. Saudin Maliqi, Thoracic Surgeon, Director of the Thoracic Surgery Clinic at the University Clinical Center of Kosovo. Dr. Maliqi shares almost the same opinion as the three interviewees above. He expresses his concern about the negligence of the Ministry of Health and its policies on this issue that according to him has a growing trend and that Kosovo lags far behind in this area with countries in the region. He believes that the approach and policies of the Ministry of Health should be changed and further considers that a new Oncology Clinic should be built, which includes prevention, therapeutic and laboratory treatment, operative treatment of all types and palliative care. According to him, only this new organizational form and approach consolidates and increases the efficiency of prevention, adequate treatment and fight against cancer in Kosovo.

Dr. Serbeze Kabashi - Mucaj, PhD, Radiology Specialist at the Clinic of Radiology (UCCK), considers that the conflict and its consequences have had and continue to have an impact on the consolidation of medical fields that deal with cancer in Kosovo. She raises her concern about the lack of application of modern methods in diagnosing cancer. She also raised her remarks on diagnostic protocols, emphasizing in particular the lack of PET diagnosis - positron emission tomography (PET CT) of cancer in Kosovo. She blames the Ministry of Health and its inadequate policies on this issue for the lack of adequate modern technology, the insufficient budget for the treatment of cancer in Kosovo.

As for the challenges of diagnosing and adequately treating cancer in Kosovo, Dr. Labinot Shahini, PhD, pathology specialist at the UCCK Institute of Pathology expresses almost the same opinions as his colleagues in the respective fields. He considers that the impact of the conflict has greatly damaged the adequate and multidimensional treatment of cancer in Kosovo. According to him, the policies of the Ministry of Health and lack of coordination with the National Board of Cancer Control and Oncology Clinic, inadequate approach and lack of necessary budget have affected this major health care challenge in Kosovo to be below the desired level. The lack of modern technology for adequate diagnosis and the lack of palliative care are serious challenges for patients, health professionals and the health system in general, says Dr. Shahini.

As one of the challenges of the Kosovo health system, cancer continues to be a public health challenge in Kosovo. Regarding the issues we have addressed in our research, Dr. Sefedin Mucaj, PhD, Public Health Specialist at the National Institute of Public Health of Kosovo sees as a serious problem the effect of the conflict on the stagnation of the Kosovo health system in the adequate fight against cancer, socio-political circumstances and economic development of Kosovo and lack of proper coordination of relevant institutions that deal professionally with this issue. He in particular raises the concern about the lack of adequate statistics from all relevant health institutions that address this issue, then the lack of Kosovo health statistics in the ECDC and WHO, the lack of cooperation with these important international health institutions and the lack of palliative care that according to him increases the number of cancer deaths in Kosovo.

\section{Results}

From the results we received from the questionnaires conducted in electronic form, we received interesting answers about certain issues, about the effects of the conflict on the development and advancement of oncology in general and palliative care in particular, but also about the responsibility of the Ministry of Health and its policies about this issue. We will discuss all the answers, in particular the considerations of the respondents on the specific questions on which we have raised the hypotheses of this paper.

The answers to the first question are opinions of health professionals who also have managerial responsibilities in this field of public health in Kosovo, and over $85 \%$ consider that the impact of the conflict has had a major impact in all segments of prevention, diagnosis, treatment as well as combating cancer.

The second question, and the percentages of answers presented in Graph No 2, are realistic estimates, as only after the end of the conflict, Kosovo has built infrastructure and professional capacities that deal professionally with this issue, although $28.60 \%$ of

Page 11/20 
health professionals interviewed are more reserved as far as this issue is concerned.

Answers to question No. 3, are unanimous assessments of health professionals that the health system of Kosovo at all three levels of organization partially meets the needs of patients in terms of infrastructure needed to fight cancer, which confirms our hypotheses regarding the effects of conflict in this area of the health system of Kosovo.

Inter-institutional coordination continues to be inadequate between the responsible institutions that cover this area of Kosovar health, this has been witnessed by the responses of respondents presented in Graph No. 4.

In question no. 5. There are different assessments about the protocols and adequate treatment with modern methods and standard therapies, depending on the specialist areas covered by the respondents. Oncology specialists consider that the necessary modern protocols have been approved and the treatment is provided with standard therapy, $42,90 \%$ of the respondents have this opinion, while some of the respondents, especially from the field of radiology and surgery, have remarks about the protocols, treatment and modern therapy. Their remarks and hesitations are reflected at $57.10 \%$.

Answers to question No. 6, are unanimous opinions of health professionals that the health system of Kosovo has no palliative care at all, which confirms our hypotheses regarding the effects of conflict in this area of the health system of Kosovo.

Regarding the incidence and prevalence of cancer in Kosovo, oncology specialists estimate that they are concerned, but that these trends are almost similar to other countries in the Western Balkans region and countries in transition, while professionals in other fields who treat this issue are very concerned with these trends and have expressed this concern with $29 \%$, presented in graph no. 7.

About the unfavorable situation and challenges that health professionals face in their daily confrontation with the fight against cancer, they now blame more than two decades after the end of the war and 13 years after the declaration of independence the Ministry of Health and its policies in this area with $57.10 \%$. Political circumstances and post-conflict transition and their consequences in the field of health are assessed as harmful by $14.30 \%$, while all three components together, including the responsibility of health professionals are expressed by $28.60 \%$ of respondents surveyed, reflected in graph No. 8 .

\section{Conclusions And Discussion}

Based on the literature review, analysis of interviews and questionnaires as well as referring to official data of Kosovo institutions that address this issue, we may conclude that the effects of the destruction of the health system infrastructure during the conflict in Kosovo, the isolation and lack of building the necessary capacity of health personnel, the lack of sustainable funding and the lack of political will of decision makers continue to be serious challenges to the Kosovo health system in general and palliative in particular.

The consequences of the conflict significantly complicate the enhancement and reforms in the health system of a country, especially in the areas of tertiary health care that require political will, sustainable and continuous funding, continuous education of health personnel, therapy based on modern protocols and advanced equipment, which the Kosovo health system and palliative care currently lack.

Budget allocations for the period 2015 - 2019 that we have analyzed, although marking an increase from year to year, from $169,114,056$ Euros in 2015 to $223,460,875.15$ Euros in 2019, still have not met the needs of health care for the citizens of Kosovo in general and in prevention, early diagnosis, cancer control and palliative care in particular. Kosovo is part of the low-income countries, certainly due to the classic occupation in the period 1990-1999, as well as the consequences of the 1998-1999 conflict, the deep political and socio-economic transition under the administration of the United Nations, and the reforms in continuity, have affected for an insufficient GDP for health that for the years 2015 - 2019, including expenditures in both public and private sectors, ranges in approximate values from $5.5 \%-5.7 \%$, which in our opinion is insufficient. The budget allocated for cytostatics is insufficient, which in the period we have analyzed 2015 - 2019, has covered only $76 \%-89 \%$ of patients' needs, which creates serious problems and challenges for patients in the first place and also for professional health care providers dealing with the prevention, diagnosis and control of cancer in Kosovo.

\section{Abbreviations}

UCCK - University Clinical Center Kosovo

Page $12 / 20$ 
NGO - Non Government Organizations

UN - Unated Nations

UNMIK - UN’s Interim Administration Mission in Kosovo

EU - Eropean Union

EULEX - EU's Rule of Law Mission in Kosovo

ECDC - European Centre for Disease Prevention and Control

GDP - Gross Domestic Product.

NATO - North Atlantic Treaty Organization

KFOR - Kosovo Force

FMC - Family Medicine Center

PET - Positron Emission Tomography

UCHSK - University Clinical Hospital Service of Kosovo

WHO - World Health Organization

\section{Declarations}

\section{Ethical considerations:}

All of the research participants have agreed to be cited with their names and official credentials.

Considering that this research does not use any private data, no prior approval was required, as stipulated in the applicable law.

\section{Data availability:}

The datasets analysed during this study are available in the Figshare repository https://figshare.com/s/e938f209ab9887e563e6

\section{Funding and competing interests:}

The researchers have no applied or seeked any funding. All expenses were covered by their own private funds. There are no competing interests.

\section{Acknowledgments:}

The researchers would like to thank and acknowledge the contribution of Dr. Ilir Kurtishi, the Director of the Public Oncology Clinic in Pristina who was kind enough to support this research.

\section{Authors' contributions}

Naser Rugova <naser.rugova@ubt-uni.net>,

Shqipe Hyseni Buleshkaj (corresponding author) <shqipe.buleshkaj@rezonanca-rks.com> 
N.R was responsible for the theoretical framework and the collected data analysis. Sh.H.B was responsible for the preparation of questionnaires and the data collection process.

\section{Consent for publication}

All of the material is owned by the authors and/or no permissions/consent are/is required.

\section{References}

1. Waters H, Garrett B, and Burnham G, UNU-WIDER 2007, available at: https://www.econstor.eu/dspace/bitstream/10419/63390/1/524762260.pdf .

2. Krug, E.G., G.K. Sharma, and R. Lozano (2000). 'The Global Burden of Disease', American Journal of Public Health 90(4): 523-26.

3. LSHTM (London School of Hygiene and Tropical Medicine) (2001). 'Nursing a Country's Health System Back to Health', Department of Public Health and Policy, Research Briefing, London School of Hygiene and Tropical Medicine: London.

4. Percival V, Sondorp E. A case study of health sector reform in Kosovo. 2010; available at: https://doi.org/10.1186/1752-1505-47 .

5. Data for 2012, Eurostat, According to the Statistical Office of Kosovo, the country is inhabited mostly by Albanians ( $92 \%)$, Serbs (4\%), Bosniaks and Gorans (2\%), Turks (1\%) and Roma (1\%). The most common religious denomination is Islam (data from 2011 Census), available at: https://ask.rks-gov.net/en/kosovo-agency-of-statistics .

6. Data from 2011 Census, Kosovo Agency of Statistics (2013a), available at: https://ask.rks-gov.net/en/kosovo-agency-ofstatistics .

7. Stambolieva M. Kosovo - from State of Welfare Emergency to Welfare State? 2012; available at: http://dx.doi.org/10.2139/ssrn.2687677 .

8. Friedrich-Ebert-Stiftung, Regional Project for Labour Relations and Social Dialogue in South East Europe, "The Performance of Public Health-care Systems in South-East Europe", available at: https://library.fes.de/pdf-files/bueros/belgrad/10758.pdf .

9. Stubbs P. and Haxhikadrija A. (2008): Social Protection and Social Inclusion in Kosovo under SCR 1244, Directorate-General for Employment, Social Affairs and Equal Opportunities - European Commission, Brussels.

10. Jones I, Schneider E, and Speigelman A.J , The Nelson A Rockefeller Center at Dartmouth College, available at: https://rockefeller.dartmouth.edu/sites/rockefeller.drupalmultiprod.dartmouth.edu/files/palliativecarereportfinal_053119.pdf

11. United Nations Environment Programme, "From conflict to peacebuilding” available at: https://postconflict.unep.ch/publications/pcdmb_policy_01.pdf .

12. Debarre A, "Hard to Reach: Providing Healthcare in Armed Conflict", available at: https://reliefweb.int/sites/reliefweb.int/files/resources/1812_Hard-to-Reach.pdf .

13. Tzifakis N. "Post-Conflict Economic Reconstruction”, available at: https://pesd.princeton.edu/node/586 .

14. Harvard Medical School Department of Global Health and Social Medicine, "The Kosovo case study", available at: https://www.recoveryplatform.org/assets/publication/Kosovo_CaseStudy/Kosovo\%20Case\%20Study.pdf .

15. Ministry of Health of Republic of Kosovo, Health Sector Strategy, 2017 - 2020, available at: https://msh.rksgov.net/en/strategjite/ .

16. Kosovo - Caritas. (2018), Retrieved from: https://www.caritas.org/where-caritas-work/europe/kosovo/ .

17. The Hospital and University Clinical Service of Kosovo, Medical Oncology Clinic, availableat:https://shskuk.rksgov.net/Navbar/SubMenuContent/klinikaOnkologjiseMjekesore.

18. WHO, 2018, International Agency for Research on Cancer, available at: https://www.iarc.who.int/wpcontent/uploads/2018/09/pr263_E.pdf .

19. WHO, 2021, Cancer data, available at: https://www.who.int/news-room/fact-sheets/detail/cancer .

20. Kosovo Agency of Statistics, Causes of deaths in Kosovo 2014 and 2015, available at: https://ask.rks-gov.net/en/kosovoagency-of-statistics/add-news/causes-of-death-in-kosovo-20142015. 
21. Kosovo Agency of Statistics, Causes of deaths in Kosovo 2016 and 2017, available at: https://ask.rksgov.net/media/5303/causes-of-death-in-kosovo-2016-2017.pdf .

22. Kosovo Agency of Statistics, Causes of deaths in Kosovo 2018 and 2019, available at: https://ask.rksgov.net/media/5914/causes-of-death-in-kosovo-2018-2019.pdf .

23. Kosovo Agency of Statistics, Metadata - Health Statistics, Information received by official email from the Health Statistics analyst.

24. Information received officially through the official email from the Permanent Secretary of the Ministry of Health of the Republic of Kosovo.

\section{Figures}

Question 1: Do you think that the period 1990-1999 has seriously damaged the development of Oncology in Kosovo and other related

fields in the prevention, fight and adequate treatment of cancer in Kosovo?

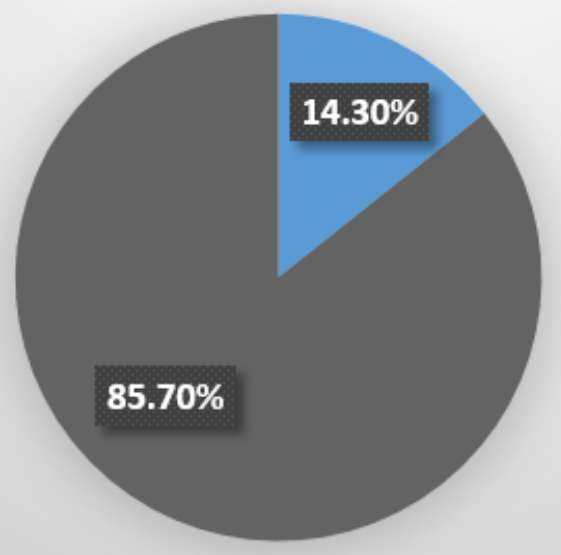

a Yes

No

- Partly

Not at all

A lot

Graph No. 1

\section{Figure 1}

Please See image above for figure legend. 
Question 2: Has Kosovar Oncology advanced as well as, its specialized and subspecialized fields related to it in the postwar period in Kosovo 1999 - 2019?

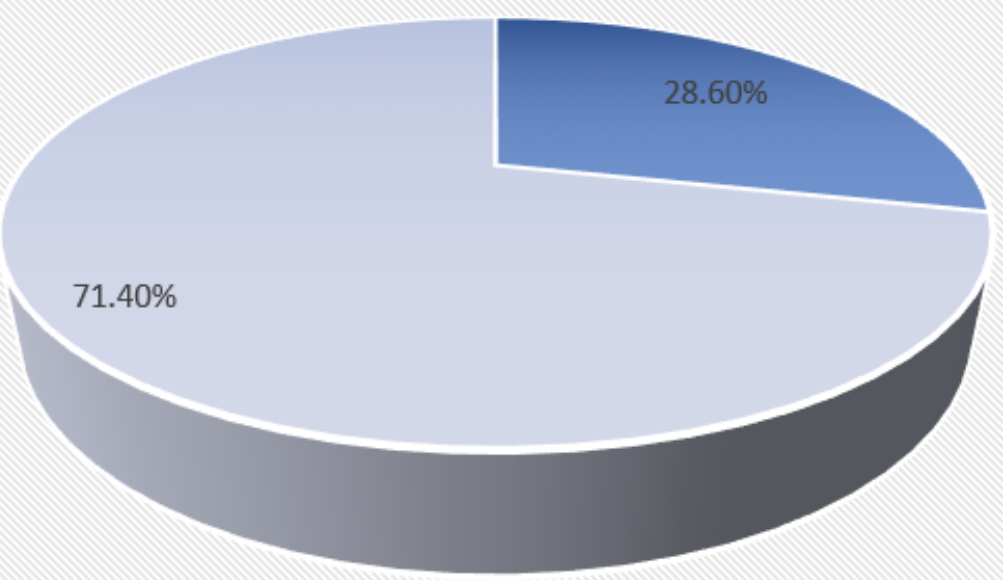

- Yes

- No

- Partly

Not at all

A lot

Graph No. 2

Figure 2

Please See image above for figure legend.

Question 3: Does Kosovo and the Institute of Oncology, but also the network of health institutions of the health system of Kosovo at all three levels of organization have adequate professional profiles, sufficient facilities, equipment and other logistics

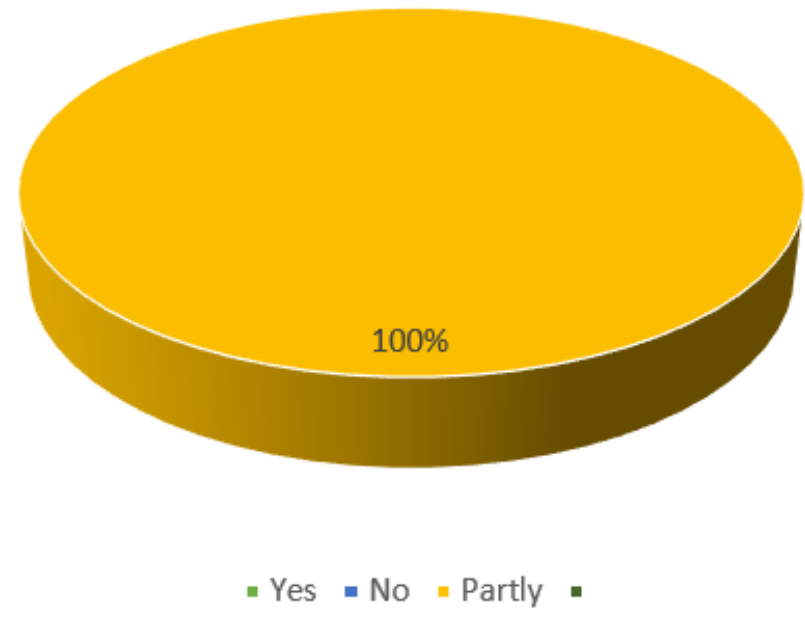

Graph No. 3 
Question 4: How do you evaluate the coordination of the Ministry of Health, the Board for Cancer Control, the Institute of Oncology and the Institutes and Clinics directly related to the treatment of cancer?

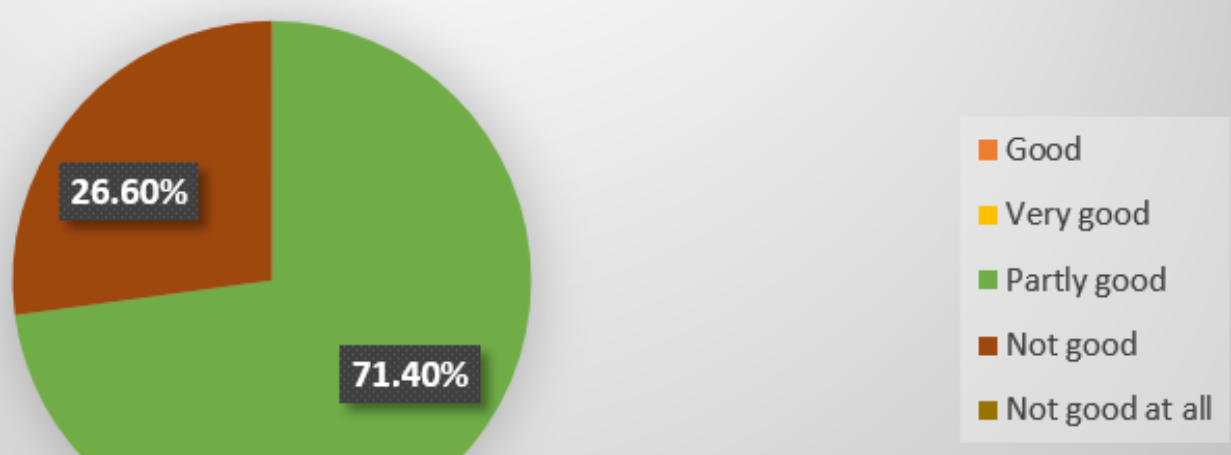

Graph No. 4

Figure 4

Please See image above for figure legend.

Question 5: Are the necessary protocols for the treatment of cancer approved, are you satisfied with their implementation, and are standard methods and therapies practiced as in other countries?

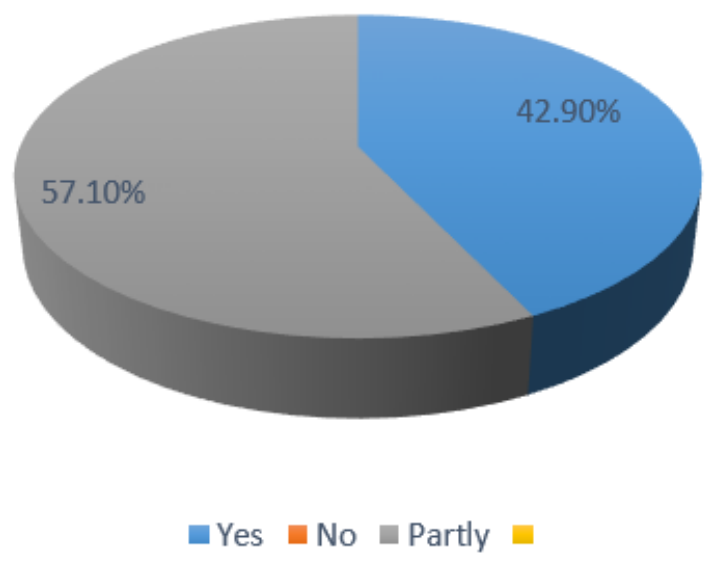

Graph No. 5. 
Figure 5

Please See image above for figure legend.

\section{Question 6: Is there palliative care in Kosovo?}

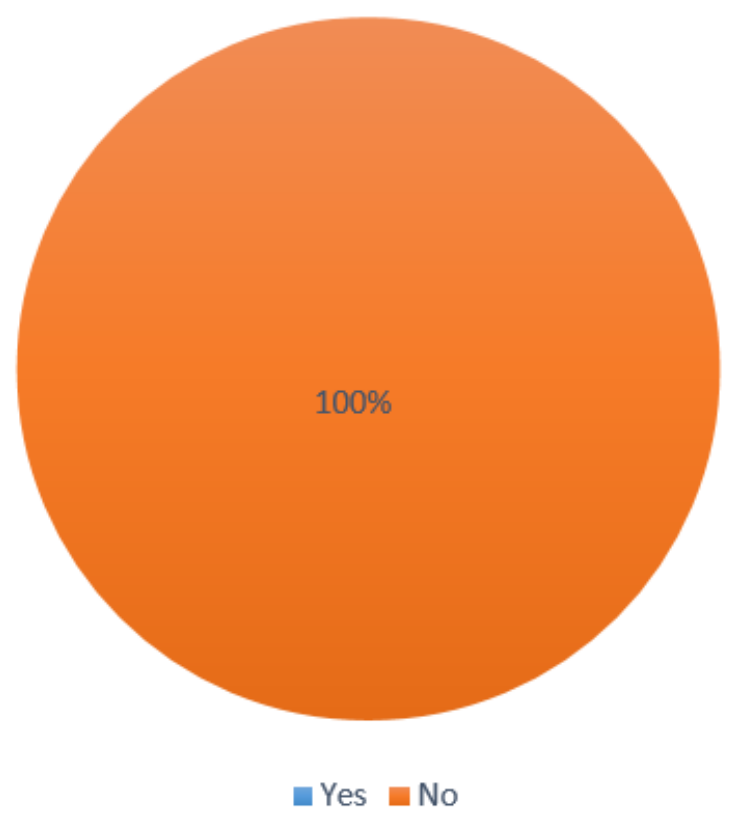

Graph No. 6

Figure 6

Please See image above for figure legend. 


\section{Question 7: Are you concerned about the incidence and prevalence of cancer in Kosovo?}

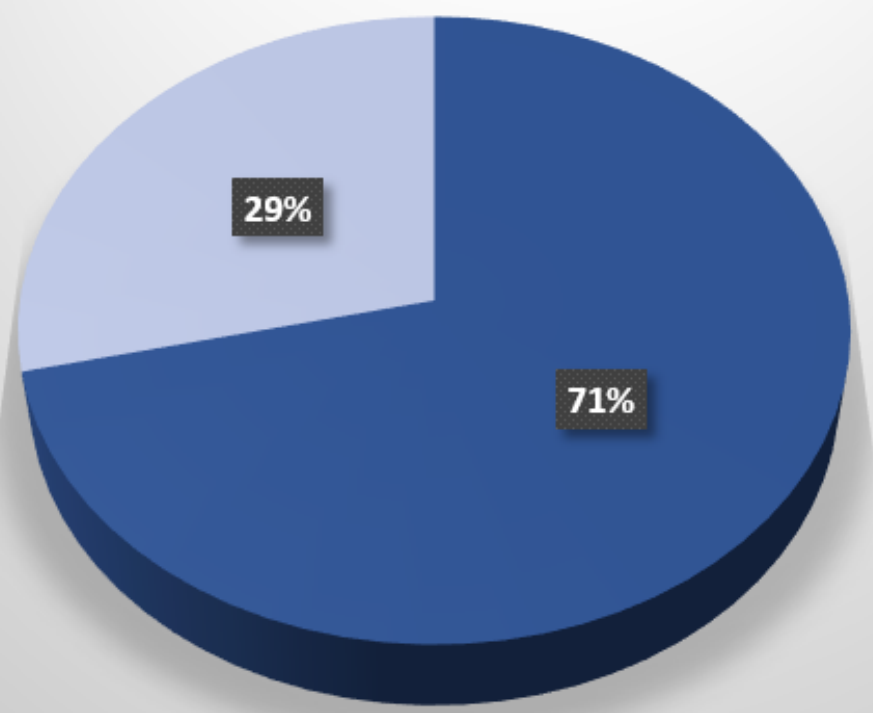

Graph No. 7

\section{Figure 7}

Please See image above for figure legend.

Question 8: Who would you blame for the challenges of prevention, adequate fight and proper treatment of cancer in Kosovo?

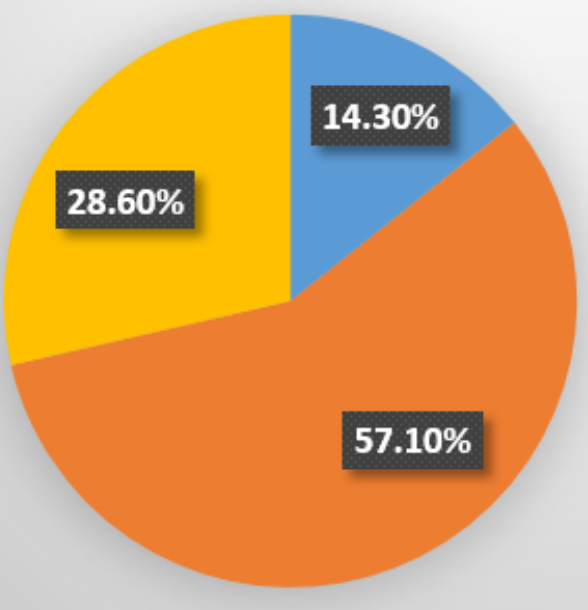

- Political circumstances andconsequences of the postconflicttransition

- Ministry of Health and its policies

- Health professionals in this field

All three components together

Graph No. 8 
Please See image above for figure legend.

Page 20/20 